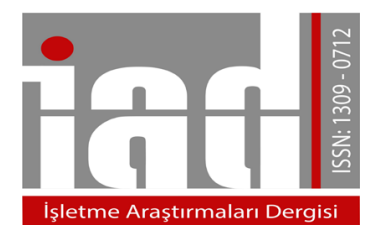

\author{
İşletme Araştırmaları Dergisi \\ Journal of Business Research-Turk \\ 10/4 (2018) 742-756
}

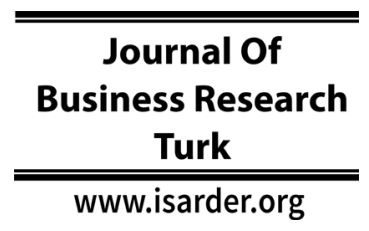

$\underline{\text { Research Article }}$

\title{
Dark Triad and Counterproductive Work Behaviors: Which of the Dark Triad Traits is More Malevolent?
}

\author{
Emrah ÖZSOY \\ Sakarya University \\ Sakarya Business School \\ Sakarya, Turkey \\ orcid.org/0000-0003-2886-8824 \\ eozsoy@sakarya.edu.tr
}

\begin{abstract}
Although the Dark Triad has begun to be studied extensively, little is known about which of the Dark Triad traits is more malevolent in organizational context. Therefore in this study in order to compare the effects of Dark Triad traits on work-related attitudes, the effects of the Dark Triad traits (i.e., narcissism, Machiavellianism, and psychopathy) on counterproductive work behaviors (CWBs) (withdrawal, theft, and abuse) were examined. $N=244$ employees participated in the study. Employees rated their own Dark Triad and CWBs. The results revealed that, in correlation analysis all the Dark Triad traits related to CWBs positively. Narcissism had the weakest correlation here (having only significant associations with withdrawal). However, according to the multiple regression findings, Machiavellianism and narcissism did not predict CWBs and only psychopathy predicted CWBs. Results were discussed and suggestions were made for further research. This study provided that comparing to narcissism and Machiavellianism, psychopathy could potentially be more malevolent in organizational context.

Keywords: Dark Triad, Narcissism, Machiavellianism, Psychopathy, Counterproductive Work Behaviors
\end{abstract}

Received 21 September 2018; Received in revised from 4 December 2018; Accepted 10 December 2018

\section{Introduction}

The dark side of personality (i.e., Dark Triad; subclinical narcissism, Machiavellianism, and subclinical psychopathy) (Paulhus \& Williams, 2002; Spain, Harms, \& LeBreton, 2014) has begun to be studied extensively in the fields of social, personality, and organizational psychology in recent years. However, it is still not yet possible to draw a clear conclusion about the organizational consequences of Dark Triad traits (Harms, \& Spain, 2015), because the effects of narcissism, Machiavellianism, and 
psychopathy on work-related attitudes are varying. Some researchers, in particular, emphasize that the likelihood of Machiavellianism and psychopathy to be negative is more than narcissism, and thus Machiavellianism and psychopathy are more likely to lead to undesirable outcomes in terms of organizations. On the other hand, narcissism is considered more positively compared to the results of Machiavellianism and psychopathy (in terms of their effects on work-related attitudes) (Volmer, Koch, \& Göritz, 2016). However, more research is still needed to be conducted to understand which Dark Triad component is more destructive and negative (Miller et al., 2016). For this reason, the current study examines the impact of the Dark Triad on CWBs. Thus in this study it is aimed a) to test the effects of the Dark Triad on workplace attitudes (i.e., CWBs) and b) to obtain more findings to understand which Dark Triad component is more negative.

\section{Conceptual Framework}

\subsection{Dark Triad}

Since Paulhus and Williams (2002) defined subclinical narcissism, Machiavellianism, and subclinical psychopathy as the Dark Triad, the number of empirical research that has been related to various issues of psychology has increased steadily. Each of these structures coincides with "disagreeableness" (Paulhus \& Williams, 2002). However they are all distinct concepts. Therefore each dimension is briefly described below.

Narcissism: Narcissism is a personality disorder defined in DSM-V (Diagnostic and Statistical Manual of Mental Disorders (DSM-V) which is published by the American Psychiatric Association (APA). However, Paulhus and Williams (2002) considered narcissism and psychopathy at a subclinical level in the Dark Triad. As a matter of fact, narcissism is measured at subclinical level in many scales developed for measuring narcissism such as Narcissistic Personality Inventory (NPI; Raskin \& Hall, 1979), Brief Narcistic Personality Inventory (NPI-16; Ames, Rose, \& Anderson, 2006), the Short Dark Triad (SD3; Jones \& Paulhus, 2014), Single Item Narcissism Scale (SINS; Konrath, Meier, \& Bushman, 2014), and the Dark Triad Dirty Dozen scale (DTDD; Jonason \& Webster, 2010). Narcissism was also measured at the subclinical level in the current study and participants were not diagnosed with personality disorder. Subclinical narcissism reflects the tendency of narcissism rather than narcissistic personality disorder. Basic characteristics of narcissists can be listed as having high level of arrogance, the tendency to establish leadership and authority towards others, the superficiality of human relations, aggressive reactions to criticism, and jealousy (APA, 2000; Jonason \& Webster, 2010; Miller \& Campbell, 2008; Miller et al., 2011; Raskin \& Hall, 1979).

Machiavellianism: Machiavellianism is based on an Italian politician and writer Niccolo Machiavelli's book called "The Prince". In the 1970s, Christie and Geis (1970) examined the book and argued that Niccolo Machiavelli's point of view in the book reflects "Machiavellian personality". The main features of the individuals with a Machiavellian personality or a high tendency to behave in a Machiavellian (High Mach) way can be listed as; exhibiting manipulative behaviors, superficial human relations, high desire to gain power, being goal-oriented, and self-centered. Therefore it can be stated that the individuals with Machiavellian personality traits demonstrate behavioral patterns that are based on tactics to gain power. They control their behaviors to be able 
to reach their goals and if necessary they can lie, cheat or behave unethically to get their way. They usually have a cynical point of view towards human nature and therefore they don't easily share information about themselves which might hinder them from getting their way (Christie \& Geis, 1970; Jones, \& Paulhus, 2009; Kessler et al., 2010; Rauthmann \& Will, 2011).

Psychopathy: Psychopathy is regarded by many researchers as a personality disorder due to its close relation with the antisocial personality disorder mentioned in DSM-V. Like narcissism, psychopathy is also usually studied at a subclinical level (Levenson, Kiehl, \& Fitzpatrick, 1995) in the field of organizational psychology. Therefore, in this study psychopathy was also measured and examined at a subclinical level. It is difficult to define psychopathy, but the main features of psychopaths or psychopathic individuals are selfishness, aggressiveness, impulsiveness, lack of remorse, superficiality of human relations, and goal orientation (Babiak, \& Hare, 2006; Hare, 1993; Mathieu et al., 2014; Smith \& Lilienfeld, 2013).

\subsection{Counterproductive Work Behaviors (CWBs)}

Depending on the existing literature, it is possible to include many issues that can be considered among CWBs. The common point of these behaviors is that employees deliberately do harm to the organizations they work with or to the individuals in the organization in various ways. Due to the reasons such as personal (e.g., personality disorder, psychological problems, and personality traits), organizational (e.g., not being satisfied with management, perceived injustice, problems with colleagues, and supervisor dissatisfaction), employees could have behaviors in the workplace such as (Fox, Spector \& Miles, 2001; Gruys \& Sackett, 2003; Spector \& Fox, 2005; Spector et al., 2006):

- Absenteeism,

- Theft and similar behaviors,

- Inappropriate physical (e.g., hitting, pushing, and engraving) and verbal (e.g., insulting and pranking) actions,

- Abusing time and information,

- Misusing company property,

- Failure to follow directions,

- Being rude to customers or colleagues

All these behaviors are considered as CWBs.

\section{Research Background}

There is limited research on examining the effects of Dark Triad Traits on CWBs. Therefore, in order to understand the possible consequences of Dark Triad better, more research on the effects of Dark Triad on workplace behaviors are needed (Harms, \& Spain, 2015). A set of hypotheses based on the theoretical and empirical background for each Dark Triad traits are presented below, respectively for narcissism, Machiavellianism, and psychopathy.

In a recent study Yin and Cohen (2018) examined the associations between the Dark Triad traits and CWBs (both at individual and organizational level), on the sample of Chinese physicians. In their research the Dark Triad traits were all found to be positively related to CWBs at both interpersonal and organizational levels except for 
psychopathy (no significant correlation with CWBs at interpersonal level). DeShong, Grant, \& Mullins-Sweatt (2015) analyzed the correlations between the Dark Triad and CWBs (both at individual and organizational level) on undergraduate psychology students (working at least 20 hours a week) sample and found that all the Dark Triad traits were positively related to both CWBI and CWBO. Kanten, Yeşiltaş, \& Arslan, (2015) examined the relationships between Dark Triad and CWBs (as a total score) on the sample of hotel employees. They found; positive associations between Machiavellianism and CWBs, no significant associations with psychopathy and CWBs and negative associations with narcissism and CWBs. As it is seen, the empirical findings are not coherent with each other thus it is not really possible to come to a clear conclusion about the associations between Dark Triad and CWBs. That is also an important reason to conduct more research to test the associations between the Dark Triad and CWBs in order to provide additional findings to the current literature. Depending on the theoretical background, for each Dark Triad traits, a short discussion of the hypothesis development presented below.

Narcissism: Narcissists are self-oriented and they continuously seek power and prestige (Konrath, 2008). Narcissists are aggressive especially when their ego is threatened (Bushman \& Baumeister, 1998). It is expected that in an organization, if narcissists can't achieve their goals, satisfy their ego and do not find enough support, they could commit some kinds of CWBs. In two Meta-analyses, narcissism was found to be positively related to CWBs. First, O'Boyle et al (2012) found a positive association (Effect size; $\mathrm{r}=0.43$ ) between narcissism and CWBs. Later on, Grijalva and Newman (2015) conducted another Meta-analysis and the effect size was a bit weaker but still significant $(\mathrm{r}=0.23)$. Additionally Penney and Spector, (2002) found a positive association between narcissism and CWBs. Therefore, depending on the theoretical and empirical background the hypothesis for narcissism has been postulated as follows.

Hypothesis 1: Narcissism is a significant predictor of CWBs.

Machiavellianism: Machiavellians are more controlled and goal-oriented than narcissists and psychopaths. These individuals can easily apply various immoral and unethical tactics when it comes to their personal interests. Under regular circumstances they tend to be less aggressive than psychopaths, because they have a high tendency to behave politically to gain more power. Therefore they tend to build close relationships with the people who have power and authority in the organization. However, it can be argued that an employee who shows a Machiavellian tendency at a severe level (High Mach) is likely to harm his or her colleagues or organization in order to attain his or her own ends. For example, Machiavellians can exhibit behaviors such as lying, smearing, and making unwanted jokes to damage the reputation of a colleague who they see as opponents. Furthermore, if there are circumstances, policies, or individuals that prevent them from getting their way, it is likely that Machiavellians can apply several unethical tactics and strategies. In previous research Machiavellianism was related to unethical behaviors (Greenbaum et al., 2014; O'Fallon \& Butterfield 2005), lying, and cheating (Dahling, Kuyumcu, \& Librizzi, 2012). In a Meta-analysis, O’Boyle et al. (2012) found that Machiavellianism was found to be positively associated with interpersonal forms of CWBs. Therefore it is expected that; 


\section{Hypothesis 2: Machiavellianism is a significant predictor of CWBS.}

Psychopathy: Psychopaths tend to be more impulsive than narcissists and Machiavellians. People with high psychopathic tendencies tend to be aggressive in social life or in the organizational setting (Boddy, 2010; Hare, Hart, \& Harpur, 1991). However, it is not possible to claim that this assumption may be applied in all cases. Because psychopaths can be extremely attractive and impressive in some situations (e.g., being promoted in an organization, obtaining and maintaining power, and hiding the impulsive tendencies), they can be considered as successful psychopaths (Hall \& Benning, 2006). On the other hand, generally psychopaths are aggressive, impulsive, and have lack of empathy. In previous research, psychopathy was positively associated with conflict (Boddy, 2014), bullying (Van Geel et al., 2017), abusive supervision (Boddy, 2010) in the workplace. Therefore it is expected that they will apply CWBs in their organizations and the hypothesis is postulated as follows;

Hypothesis 3: Psychopathy is a significant predictor of CWBs.

\section{Method}

\subsection{Sample \& Data Collection}

Participants were the employees working at different sectors in Sakarya Province, Turkey. A quantitative research was designed and a questionnaire form was created including the Turkish version of Dirty Dozen Dark Triad scale (DTDD-T), Turkish version of CWBs scale, and some additional questions (including the basic demographics features). Questionnaire forms were distributed to participants by hand (paper-pencil method) with the method of convenience sampling. Participants rated their own Dark Triad traits and counterproductive work behaviors. After eliminating the missing and sloppy questionnaire forms, a total of 244 valid questionnaires were obtained and used for further analysis. The data were collected between March 2018 and June 2018.

\subsection{Scales}

Dark Triad: The Turkish form (DTDD-T) (Özsoy, Rauthmann, Jonason, \& Ardiç, 2017) of 12-item Dark Triad Dirty Dozen (DDTD; Jonason \& Webster, 2010) was used with a five-point Likert-type response scale (1-totally disagree, 5-totally agree). Each dimension (i.e., subclinical narcissism, Machiavellianism, and subclinical psychopathy) has 4 items. Three individual scales as well as global Dark Triad dimensions reflecting general dark tendencies (Dark g) were used. Özsoy et al. (2017) tested the reliability (in terms of internal consistencies), validity [in terms of factorial (CFA) and construct validity (convergent and discriminant validity)] of the DTDD-T and concluded that the DTDD-T is valid and reliable in Turkish language. In order to test the factorial validity of DTDD-T for the current study, factor analyzes (both EFA and CFA) and internal consistency test (Cronbach' $\alpha$ ) were applied. Once again the findings again supported the validity and reliability of the scale for the current research.

Counterproductive Work Behaviors: The Turkish form (Öcel, 2010) of the 32item counterproductive work behavior scale developed by Spector et al., (2006) was used with a five-point Likert-type scale (1-never, 5-everyday). The Turkish version of the scale has four different dimensions: sabotage, withdrawal, theft, and abuse. Öcel 
(2010) examined the factor structure, reliability, and construct validity of the scale and concluded that the scale is valid and reliable in Turkish language as 32 items with four dimensions. Factor analyzes (both EFA and CFA) and internal consistency (Cronbach' $\alpha$ ) test were applied for also the current study. The number of items and dimensions were reduced after factor analysis for the current research. After factor analysis the sabotage dimensions had to be omitted also 2 items from abuse dimension "been nasty or rude to a client or customer", "made an obscene gesture (the Finger) to someone at work" and one item "stolen something belonging to your employer" from theft dimension had to be omitted. Thus in the current research the scale had 3 dimensions (withdrawal with 6 items, theft with 5 items, and abuse with 15 items) and 26 items. Three individual scales, as well as global CWB dimensions reflecting general counterproductive work behavior tendencies (CWBs g) were used in the current study.

\subsection{Results}

Demographic characteristics of the participants presented in Table 1. Factor analysis findings (in terms of both exploratory and confirmatory factor analyzes to test the factorial validity of the scale) are displayed in Table 2 (for DTDD-T) and Table 3 (for CWBs scale). Descriptive statistics $(M, S D)$ and internal consistency scores $(\alpha)$ are shared in Table 4. The correlations analysis findings are displayed in Table 5. The findings for the hypotheses which were tested with multiple regression analysis are displayed in Table 6.

Table 1: Demographic Characteristics of the Participants

\begin{tabular}{cccc}
\hline Variables & Category & $\boldsymbol{N}$ & $\boldsymbol{\%}$ \\
\hline \multirow{3}{*}{ Gender } & Male & 112 & 45.9 \\
& Female & 128 & 52.5 \\
& Missing & 4 & 1.6 \\
\cline { 2 - 4 } Marital Status & Married & 151 & 61.8 \\
& Single & 88 & 36.1 \\
Sector & Missing & 5 & 2.1 \\
\cline { 2 - 4 } & Public & 109 & 44.7 \\
\multirow{4}{*}{ Employee Category } & Private & 135 & 55.3 \\
\cline { 2 - 4 } & Blue Collar & 94 & 38.5 \\
& White Collar & 143 & 58.6 \\
& Missing & 7 & 2.9 \\
\cline { 2 - 4 } Education & High School and less & 23 & 34.9 \\
& Associate's degree & 104 & 9.4 \\
& Bachelor & 32 & 42.6 \\
& Master and Ph.D & 12.1 \\
\hline
\end{tabular}

Participants were 244 employees; $52.5 \%$ female; $58.6 \%$ Caucasian; $61.8 \%$ married; $55.3 \%$ from private sector, $42.6 \%$ hold a bachelor degree (Table 1). Additional details about the participants are; age: $M=31.5, S D=8.13$, range $=19-60$ years; tenure (total): $M=10.2, S D=9.33$, range $=1-41$ years; tenure (in the current organization): $M=5.55, S D=5.24$, range $1-31$ years; average monthly income $=3077$ Turkish Liras (with the current exchange rate it is approximately 581 USD, November 2018) (Table 4).

In order to test the factor structure of both DTDD-T and CWBs scales, firstly Exploratory Factor analysis was applied. After that a Confirmatory Factor Analysis was also applied for both scales. 
Table 2: EFA and CFA Results for DTDD-T

\begin{tabular}{|c|c|c|c|c|}
\hline \multicolumn{5}{|c|}{ EFA Results For DTDD-T } \\
\hline & Values & Dimensions & $\begin{array}{c}\text { Factor } \\
\text { loadings } \\
\text { [Range] }\end{array}$ & $\begin{array}{c}\text { Total } \\
\text { Variance } \\
\text { explained }^{\mathrm{a}}\end{array}$ \\
\hline$(\mathrm{KMO})$ & 0.78 & Narcissism & {$[.73-.83]$} & $21.81 \%$ \\
\hline Bartlett's Test. Approx. Chi-Squ. & 1100.93 & Machivelianism & {$[.73-.81]$} & $20.74 \%$ \\
\hline df & 66 & Psychopathy & {$[.54-.87]$} & $20.73 \%$ \\
\hline Sig. & $* * *$ & Total & {$[.54-.87]$} & $63.28 \%$ \\
\hline \multicolumn{5}{|c|}{$\begin{array}{c}\text { A Three Factor Solution CFA Fit Indexes For DTDD-T } \\
\end{array}$} \\
\hline \multirow{2}{*}{$\begin{array}{c}\chi^{2} / \mathbf{d f} \\
124.83 / 50=2.50 * * * \\
\end{array}$} & & AGFI T & CFI & RMSEA \\
\hline & & 0.88 & 0.93 & 0.08 \\
\hline
\end{tabular}

For $D T D D-T$, firstly an EFA analysis was applied. As expected, coherent with the original and adaptation study, three factor emerged and details are presented in Table 2. $\mathrm{KMO}$ value $=0.78$; Bartlest Test $=\mathrm{p}<0.000$; Total variance explained $=63.28 \%$; factor loadings ranged from 0.54 to 0.87 ; Total variance explained per dimensions; narcissism $21.81 \%$, Machiavellianism $20.74 \%$, and psychopathy $20.73 \%$. After EFA, a CFA was also applied and a three factor model fit the data well (with three factor solution) $\left(\chi^{2} / \mathrm{df}\right.$; 124.83/50=2.50; $\mathrm{p}<0.000$; GFI $=0.92$; AGFI $=0.88$; $\mathrm{TLI}=0.91 ; \mathrm{CFI}=0.93$; $\mathrm{RMSEA}=$ 0.08 ). Factor loadings ranged from 0.46 to 0.95 . These findings are at the acceptable level and supported the factorial validity of the scale. More details are presented in Table 2 .

Table 3: EFA and CFA Results for CWBs Scale

\begin{tabular}{|c|c|c|c|c|}
\hline \multicolumn{5}{|c|}{ EFA Results For CWBs Scale } \\
\hline & Values & Dimensions & $\begin{array}{c}\text { Factor } \\
\text { loadings } \\
\text { [Range] }\end{array}$ & $\begin{array}{c}\text { Total } \\
\text { Variance } \\
\text { explained }^{\mathrm{a}}\end{array}$ \\
\hline$(\mathrm{KMO})$ & 0.94 & Abuse & {$[.57-.84]$} & $34,93 \%$ \\
\hline Bartlett's Test. Approx. Chi-Squ. & 6370.39 & Withdrawal & {$[.55-.75]$} & $16.20 \%$ \\
\hline df & 325 & Theft & {$[.51-.83]$} & $18.40 \%$ \\
\hline Sig. & $* * *$ & Total & {$[.51-.84]$} & $69.53 \%$ \\
\hline \multicolumn{5}{|c|}{ A Three Factor Solution CFA Fit Indexes For CWBs Scale } \\
\hline \multirow{2}{*}{$\begin{array}{c}\chi^{2} / \mathbf{d f} \\
929.878 / 263=3.54 * * *\end{array}$} & & AGFI & CFI & RMSEA \\
\hline & & 0.72 & 0.89 & 0.10 \\
\hline
\end{tabular}

For $C W B s$ scale at first, an EFA analysis was applied and as expected four dimensions were emerged. However the distribution of the items was not coherent with the adaptation study. It was mainly because of the sabotage dimension. Because only one sabotage item was representing the whole factor. Then this item was omitted but still the rest two items of sabotage had low factor loadings (less than 0.40) and these two items were under other factors. Therefore the remaining 2 sabotage items were also omitted. After this elimination, an EFA was run again and three factors emerged. However 1 item from theft dimension and two items from abuse dimension had less than 0.40 factor loadings. Therefore respectively those three items were also omitted. After that, with 26-item and 3 factors coherent with the adaptation study was emerged.

Although via EFA, the scale was reduced to 3 factors and 26 items, at first a CFA was applied to CWBs scale with a four factor solution (as it is proposed as a four factor 
scale in adaptation study) with 32 items. However, very poor fit indexes were achieved, once again mainly because of the sabotage dimension. After that a CFA analysis was applied to 26 items with 3 dimensions as obtained via EFA. The fit indexes were at acceptable level for $\chi^{2} / \mathrm{df}$, CFI, and TLI, however for GFI, AGFI, and RMSA the indexes were poor $\left(\chi^{2} / \mathrm{df} ; 929,878 / 263=3.54 ; \mathrm{p}<0.000\right.$; GFI $=0.77$; AGFI $=0.72$; TLI $=$ 0.88 ; CFI $=0.89$; RMSEA $=0.10)$. It could be a problem of sample size or the number of items was not balanced as abuse dimension had 15 items whereas others had either 5 or 6 items. Consequently although the fit indexes were poor for few indicators, depending on EFA results it could be still considered that the factor structure of CWBs is acceptable with the revised form. More details are presented in Table 3. Eliminated items for abuse dimension; "been nasty or rude to a client or customer" and "made an obscene gesture (the Finger) to someone at work". Eliminated item was for theft dimension; "stolen something belonging to your employer".

Table 4. Descriptive Statistics and Internal Consistency Scores

\begin{tabular}{lccc}
\hline \multicolumn{1}{c}{ Variables } & Mean & SD & Cronbach's $\boldsymbol{\alpha}$ \\
\hline Dark Global & 2.28 & 0.68 & .80 \\
Narcissism & 2.68 & 1.00 & .79 \\
Machiavellianism & 2.29 & 0.99 & .82 \\
Psychopathy & 2.14 & 0.93 & .78 \\
\hline CWBs & 1.46 & 0.61 & .97 \\
Withdrawal & 1.42 & 0.64 & .91 \\
Theft & 1.41 & 0.66 & .85 \\
Abuse & 1.46 & 0.67 & .96 \\
\hline Additional questions & Mean & SD & Range \\
\hline Age & 31.5 & 8.13 & {$[19-60]$} \\
Income (monthly) & 3077.17 & 1741.95 & {$[1200-13000]$} \\
Tenure (Total) & 10.2 & 9.33 & {$[1-41]$} \\
Tenure (Current Organization) & 5.55 & 5.24 & {$[1-31]$} \\
\hline
\end{tabular}
Note. $N=244$

As can be seen in Table 4, overall, all scales achieved good internal consistency reliabilities (i.e., a minimum of .72). As a mean value, participants scored at the low level for all variables.

Table 5. Inter-correlations

\begin{tabular}{|c|c|c|c|c|c|c|c|c|}
\hline \multirow{2}{*}{ Variables } & \multicolumn{4}{|c|}{ Dark Triad } & \multicolumn{4}{|c|}{ CWBs } \\
\hline & Dark g & $\mathbf{N}$ & $\mathbf{M}$ & $\mathbf{P}$ & Global & $\mathbf{W}$ & $\mathbf{T}$ & $\mathbf{A}$ \\
\hline \multicolumn{9}{|l|}{ Dark Triad } \\
\hline Global Dark g & - & & & & & & & \\
\hline $\operatorname{Narcissism}(\mathrm{N})$ & - & - & & & & & & \\
\hline Machiavellianism (M) & - & $.40 * * *$ & - & & & & & \\
\hline Psychopathy (P) & - & $.38 * * *$ & $.48 * * *$ & - & & & & \\
\hline \multicolumn{9}{|l|}{$C W B s$} \\
\hline Global CWBS & $.25 * * *$ & .08 & $.20 * *$ & $.24 * * *$ & - & & & \\
\hline Withdrawal (W) & $.24 * * *$ & $.13 *$ & $.14 *$ & $.19^{* *}$ & - & - & & \\
\hline Theft $(\mathrm{T})$ & $.25 * * *$ & .04 & $.20 * *$ & $.20 * *$ & - & $.82 * * *$ & - & \\
\hline Abuse (A) & $.24 * * *$ & .06 & $.20 * *$ & $.25 * * *$ & - & $.70 * * *$ & $.71 * * *$ & - \\
\hline
\end{tabular}

As can be seen in Table 5, the dark g-factor was positively correlated with all CWB sub-scales as well as the global score. For narcissism, there was only one positive correlation with withdrawal. The rest of the CWB sub-dimensions as well as the global score of CWBs did not associate with narcissism. In terms of Machiavellianism and psychopathy there were positive correlations with all CWB sub-scales as well as the 
global score and psychopathy had the strongest effects size with CWBs. As expected the sub-dimensions of CWBs were all strongly related with each other. Similarly all the Dark Triad traits were associated with each other positively similar to previous research (Ardıç \& Özsoy, 2016; Jakobwitz \& Egan, 2006; Paulhus \& Williams, 2002).

Table 6. Multiple Regressions

\begin{tabular}{|c|c|c|c|c|c|c|c|c|}
\hline \multirow{3}{*}{ Predictors $^{a}$} & \multicolumn{8}{|c|}{ Outcomes } \\
\hline & \multicolumn{2}{|c|}{ Global CWBs } & \multicolumn{2}{|c|}{ Withdrawal } & \multicolumn{2}{|c|}{ Theft } & \multicolumn{2}{|c|}{ Abuse } \\
\hline & $\beta$ & $t$ & $\beta$ & $t$ & $\beta$ & $t$ & $\beta$ & $t$ \\
\hline \multicolumn{9}{|l|}{ Dark Triad } \\
\hline Narcissism & -.04 & -0.57 & .06 & 0.86 & -.08 & -1.13 & -.07 & -1.00 \\
\hline Machiavellianism & .12 & 1.56 & .05 & 0.68 & .14 & 1.87 & .13 & 1.72 \\
\hline Psychopathy & .20 & $2.73 * *$ & .14 & 1.91 & .14 & 1.92 & .21 & $2.97 * *$ \\
\hline \multicolumn{9}{|l|}{ Model Summary } \\
\hline $\mathrm{R}$ & \multicolumn{2}{|r|}{.26} & \multicolumn{2}{|c|}{.21} & \multicolumn{2}{|c|}{.24} & \multicolumn{2}{|c|}{.28} \\
\hline $\mathrm{R}^{2}$ & \multicolumn{2}{|r|}{.07} & \multicolumn{2}{|c|}{.04} & \multicolumn{2}{|c|}{.06} & \multicolumn{2}{|c|}{.08} \\
\hline Adjusted $R^{2}$ & \multicolumn{2}{|r|}{.06} & \multicolumn{2}{|c|}{.03} & \multicolumn{2}{|c|}{.05} & \multicolumn{2}{|c|}{.06} \\
\hline Std. Err.of the Est. & \multicolumn{2}{|r|}{.59} & \multicolumn{2}{|c|}{.64} & \multicolumn{2}{|c|}{.63} & \multicolumn{2}{|c|}{.65} \\
\hline \multicolumn{9}{|l|}{ ANOVA Results } \\
\hline Sum of Square & \multicolumn{2}{|c|}{6.10} & \multicolumn{2}{|c|}{4.38} & \multicolumn{2}{|c|}{5.07} & \multicolumn{2}{|c|}{8.23} \\
\hline df & \multirow{2}{*}{\multicolumn{2}{|c|}{$\begin{array}{c}3 \\
2.03\end{array}$}} & \multicolumn{2}{|c|}{3} & \multirow{2}{*}{\multicolumn{2}{|c|}{3}} & \multicolumn{2}{|c|}{3} \\
\hline Mean Square & & & & & & & & .74 \\
\hline $\mathrm{F}$ & \multicolumn{2}{|r|}{5.75} & \multicolumn{2}{|c|}{$\begin{array}{l}1.45 \\
3.53\end{array}$} & \multicolumn{2}{|c|}{4.26} & & .54 \\
\hline Sig & & $* *$ & & & & & & ** \\
\hline
\end{tabular}

For multiple regression findings, 12 different models were run: three predictor group (Narcissism, Machiavellianism, and psychopathy) $\times$ four different outcomes (global CWBs, withdrawal, theft, and abuse). As can be gleaned from the regression findings (Table 6), only psychopathy had a positive effect on CWBs' total score ( $\beta=$ $0.20 ; p<0.01)$, as well as the abusive $(\beta=0.21 ; p<0.01)$ dimension of CWBs, and there were no other significant effects. In other words, only psychopathy was a significant predictor of CWBs whereas narcissism and Machiavellianism did not predict CWBs when the other variables were controlled. This finding supports that psychopathy is the most malevolent aspect of the Dark Triad traits in terms of CWBs. Therefore, $\mathbf{H}_{\mathbf{1}}$ and $\mathbf{H}_{2}$ were both rejected, yet only $\mathbf{H}_{3}$ was supported (Table 6).

According to ANOVA results, as it is seen the effects of the Dark Triad traits on; CWBs total score $\left(\mathrm{R}^{2}\right.$ is $7 \%$, adjusted $\mathrm{R}^{2}$ is $\left.6 \%, \mathrm{p}<0.01\right)$, withdrawal $\left(\mathrm{R}^{2}\right.$ is $4 \%$, adjusted $R^{2}$ is $\left.3 \%, p<0.05\right)$, theft $\left(R^{2}\right.$ is $6 \%$, adjusted $R^{2}$ is $\left.5 \%, p<0.01\right)$, and $\left(R^{2}\right.$ is 8 $\%$, adjusted $\mathrm{R}^{2}$ is $7 \%, \mathrm{p}<0.001$ ) are all significant. But when $\mathrm{R}^{2}$ ratios (both regular and adjusted $\mathrm{R}^{2}$ values) are examined in terms of the combined effects of all Dark Triad traits on CWBs and its dimensions, it is possible to state the Dark Triad explains only a very small percentage of the variation of CWBs (around $5 \%$ ). The detailed Multiple Regression results are presented in Table 6.

\section{Discussion \& Conclusion}

All of the Dark Triad traits correlated positively with CWBs' global score (narcissism only positively related to withdrawal). However, in multiple regression analysis, only psychopathy was found to be a significant predictor of CWBs, whereas narcissism and Machiavellianism didn't predict CWBs. Psychopathy had a positive effect on CWBs globally as well as the abusive dimension of CWBs. Therefore $\mathrm{H}_{1}$ and 
$\mathrm{H}_{2}$ were both rejected and $\mathrm{H}_{3}$ was supported. DTDD-T was found both reliable and valid coherent with the original version and its Turkish adaptation. However the sabotage dimension, one item from theft dimension and two items from abuse dimension had to be omitted from the Turkish version of CWBs scale after EFA.

Interpretation of findings: Research findings show that psychopathy may potentially lead to more destructive outcomes in an organizational setting. Psychopaths are impulsive, callous, aggressive, and lack of empathy (Babiak \& Hare, 2006; Boddy, 2011), which therefore might make it easier for them to commit various offenses and commit CWBs in their organizations. This finding is expected because in a recent study, it is emphasized that psychopathy is the most destructive dark personality trait (Miller et al., 2016). Similarly, Furnham, Richards, and Paulhus (2013) examined the Dark Triad research from 2002 to 2013 and emphasized that psychopathy is more dangerous than the other two dark personality traits. Considering the existing empirical findings, it is not possible to state which of the Dark Triad traits effects CWBs stronger as the findings are not coherent with each other yet. Yin and Cohen (2018) found that narcissism and Machiavellianism were both positively related to CWBs at individual level (CWBI), whereas psychopathy did not significantly associate with CWBI. DeShong, Grant, \& Mullins-Sweatt (2015) found that all the Dark Triad traits were positively related to both CWBI and CWBO. Kanten, Yeşiltaş, \& Arslan, (2015) found positive associations with Machiavellianism and CWBs and no correlation with psychopathy and negative correlation with narcissism. These different findings obtained in previous research could be because of professional or cultural differences. In the current research, although the Dark Triad were mainly positively associated with CWBs, only psychopathy had a positive effect on CWBs (at organizational level) in multiple regression analysis. However it is clear that more research should be carried out for a more comprehensive conclusion.

In the case of narcissism, it is important to state that the findings obtained in the current research are not coherent with previous findings. This could be because of two reasons. First, the tendency of being aggressive increases more when narcissists are severely criticized and their ego is threatened (Bushman \& Baumeister, 1998). Generally speaking, it is expected that narcissists will be more likely to have negative effects on people who are in a close proximity to themselves (e.g., subordinates, coworkers, and customers). However, if they have people in the organizational environment who support their egoistic nature (e.g., people who have strong, successful and highly profitable positions), narcissists may be less inclined to become aggressive and harm the people around them. Second, in their Meta-analysis, Grijalva \& Newman (2015) and O'Boyle et al., (2012) mainly examined the independent papers coming from Western societies. However, Turkey is a more collectivist society than many other Western countries. In collectivist societies, especially where in-group collectivism (IGC) is high, narcissists engage in CWBs less (Grijalva \& Newman, 2015; O'Boyle et al., 2012). This has yielded a similar result in another study conducted in Turkey sample (see., Kanten, Yeşiltaş, \& Arslan, 2015). Furthermore, some researchers have emphasized that narcissism is the bright side of the dark side (Volmer, Koch, \& Göritz, 2016). For Machiavellianism, the results obtained in the current study were not totally in the expected direction. As explained earlier in the manuscript, Machiavellianism had a positive correlation with CWBs (DeShong, Grant, \& Mullins-Sweatt 2015; Yin \& Cohen, 2018). But when narcissism and psychopathy were controlled in the multiple 
regressions, the effects of Machiavellianism became weaker due to the stronger association between psychopathy and CWBs.

It is still not easy to propose some tactics and methods to cope with dark personality traits in organizations. Although psychopathy was found to be a stronger predictor of CWBs in the current research, narcissism and Machiavellianism were also both found to be positively related to CWBs. That means dark personality traits are needed to be critically examined and managed in organizations. However it is really hard to do that due to some important reasons. People with dark personality trait tendencies create their own advantages in recruitment interviews. This makes them to get hired easier and also to promote higher positions in organizations (Özsoy, 2017). Also due to their manipulative nature, applying standard personality tests are not the best solution as they are likely to manipulate self-reported measures.

Limitations of the research: There are several limitations that need to be stated. First, the research does not focus on a particular sector and the research only includes a small number of sample size. Second in order to measure the Dark Triad a short version of Dark Triad scale has been used. Although its psychometric properties have been proven in many other languages (e.g., Czarna et al., 2015; Küfner, Dufner, \& Back, 2015), it still can't include all the dimensions of each Dark Triad traits. Third there was no mediator or moderator variable to test the situational effects of Dark Triad. For example if a narcissistic has enough narcissistic suppliers, then it might lead a different result. If his/her ego is not threatened in the organizations, it might not be possible to perceive the possible darker aspect of a narcissistic. Therefore examining the mediating or moderating role of variables such as position, power, and social relationships would be a significant contribution.

Future research suggestions: The current research doesn't provide any findings on the consequences of personality traits of employees who have a managerial position and who don't. The effects of some other individual differences on CWBs can be examined in order to understand the individual predictors of CWBs better. Thus in future research, the effects of Dark Triad on CWBs should be examined in various levels (e.g., bottom line, middle, and top management or blue-collar vs. white-collar). Also the role of cultural differences on the effect of the Dark Triad on work-related attitudes should be examined. Especially a comparison of the effects of individualist and collectivist cultures on the consequences of the Dark Triad could help to understand Dark Triad in organizational setting better. A specific research suggestion could be also proposed for Turkey sample, although for the last decade the number of Dark Triad research increase in Western societies, little is known about the consequences of dark personalities in Turkey. The moderating or mediating roles of some variables such as power, social relations, position, and self-efficacy could be also examined to understand the role of situational and individual factors on the consequences of the Dark Triad.

To sum up, among the Dark Triad traits, psychopathy was found to be a significant predictor of CWBs, and also in previous research, psychopathy was found to be adversely related to several behaviors towards the organization. Therefore, while making recruitment and promotion decisions, practitioners should carefully evaluate the dark personality traits of their employees to increase organizational efficiency, especially for psychopathy. 


\section{References}

American Psychiatric Association. (2000). Diagnostic and statistical manual of mental disorders (4th ed., text revision). Washington, DC:Author.

Ames, R., Rose, P., \& Anderson, C.P. (2006). The NPI-16 as a short measure of narcissism. Journal of Research in Personality, 40, 440-450.

Ardıç, K., \& Özsoy, E. (2016). Examining the relationships between the dark triad traits and big five personality dimensions. Fifth European Academic Research Conference on Global Business, Economics, Finance and Banking. İstanbul, Turkey.

Babiak, P., \& Hare, R. D. (2006). Snakes in suits: When psychopaths go to work. New York: Harper Collins.

Babiak, P., \& Hare, R. D. (2006). Snakes in suits. When psychopaths go to work. New York. Regan Books.

Boddy, C. R. (2010). Corporate psychopaths and organizational type. Journal of Public Affairs, 10, 300-312.

Boddy, C. R. (2011). Corporate psychopaths, bullying and unfair supervision in the workplace. Journal of Business Ethics, 100, 367-379.

Boddy, C. R. (2014). Corporate Psychopaths, Conflict, Employee Affective Well-being and Counterproductive Work Behaviour. Journal of Business Ethics 121, 10721.

Bushman, B. J. \& Baumeister, R. F. (1998) Threatened egotism, narcissism, selfesteem, and direct and displaced aggression: Does self-love or self-hate lead to violence? Journal of Personality and Social Psychology, 75, 219-229.

Christie, R., \& Geis, F. (1970). Studies in Machiavellianism. New York, NY: Academic Press.

Czarna, A. Z., Jonason, P. K., Dufner, M., \& Kossowska, M. (2016). The Dirty Dozen Scale: Validation of a Polish version and extension of the nomological net. Frontiers in Psychology: Quantitative Psychology and Measurement, 7, 445.

DeShong, H. L., Grant, D. M., \& Mullins-Sweatt, S. N. (2015). Comparing models of counterproductive workplace behaviors. Personality and Individual Differences, $74,55-60$.

Fox, S., Spector, P. E., \& Miles, D. (2001). Counterproductive work behavior (CWB) in response to job stressors and organizational justice: Some mediator and moderator tests for autonomy and emotions. Journal of Vocational Behavior, 59, $1-19$.

Furnham, A., Richards, S. C., \& Paulhus, D. L. (2013). The Dark Triad of personality: A 10-year review. Social and Personality Compass, 7, 199-216.

Greenbaum, R. L., Hill, A., Mawritz, M. B., \& Quade, M. J. (2014). Employee Machiavellianism to unethical behavior: The role of abusive supervision as a trait activator. Journal of Management, 43, 585-609. 
Grijalva, E., \& Newman, D. A. (2014). Narcissism and Counterproductive Work Behavior (CWB): meta-analysis and consideration of collectivist culture, big five personality, and narcissism's facet structure. Applied Psychology: An International Review. 64, 93-126.

Gruys, M. L., \& Sackett, P. R. (2003). Investigating the dimensionality of counterproductive work behavior. International Journal of Selection and Assessment, 11, 30 -41.

Hall, J. R., \& Benning, S. D. (2006). The "Successful" psychopath: Adaptive and subclinical manifestations of psychopathy in the general population. C.J. Patrick (Ed.), Handbook of psychopathy, Guilford, New York. 459-478.

Hare, R. D. (1993). Without conscience: The disturbing world of the psychopaths among us. New York, NY: Guilford Press.

Hare, R. D., Hart, S. D. \& Harpur, T. J. (1991). Psychopathy and the DSM-IV criteria for antisocial personality disorder. Journal of Abnormal Psychology, 100, 391398.

Jakobwitz, S., \& Egan, V. (2006). The Dark Triad and normal personality traits. Personality and Individual Differences, 40, 331-339.

Jonason, P. K., \& Webster, G. D. (2010). The Dirty Dozen: A concise measure of the Dark Triad. Psychological Assessment, 22, 420-432.

Jones, D, N., \& Paulhus, D. L. (2009). “Chapter 7. Machiavellianism” In Leary, Mark R.; Hoyle, Rick H. Handbook of Individual Differences in Social Behavior. New York/London: The Guilford Press. pp. 257-273.

Jones, D. N., \& Paulhus, D. L. (2009). Machiavellianism. In M. R. Leary \& R. H. Hoyle (Eds.), Handbook of Individual Differences in Social Behavior (pp. 93-108). New York: Guilford.

Jones, D. N., \& Paulhus, D.L. (2014). Introducing the Short Dark Triad (SD3): A brief measure of dark personality traits. Assessment, 21, 28-41.

Kanten, P., Yeşiltaş, M., \& Arslan, R. (2015). Kişiliğin karanlık yönünün üretkenlik karşıtı iş davranışlarına etkisinde psikolojik sözleşmenin düzenleyici rolü. Atatürk Üniversitesi İktisadi ve İdari Bilimler Dergisi, 29, 931-259.

Kessler, S. R., Bandelli, A. C., Spector, P. E., Borman, W. C., Nelson, C. E., \& Penney, L. M. (2010). Re-examining Machiavelli: A three dimensional model of Machiavellianism in the workplace. Journal of Applied Social Psychology, 40, 1868-1896.

Konrath, S. H. (2008). Egos inflating over time: Rising narcissism and it implications for self-construal, cognitive style, and behavior. Dissertation Abstracts International B: The Sciences and Engineering, 7024 (derived from https://deepblue.lib.umich.edu/bitstream/handle/2027.42/57606/skonrath_2.pdf? sequence $=2$ )

Konrath, S., Brian, P. M., \& Bushman, B. J. (2014). Development and validation of the Single Item Narcissism Scale (SINS). PLoS ONE, 9, 8. 
Küfner, C. P., Dufner, M., ve Back, M. D. (2015). Das Dreckige Dutzend und die Niederträchtigen Neun Kurzskalen zur Erfassung von Narzissmus, Machiavellismus und Psychopathie. Diagnostica, 61, 76-91.

Levenson, M. R., Kiehl, K. A., \& Fitzpatrick, C. M. (1995). Assessing psychopathic attributes in a noninstitutionalized population. Journal of Personality and Social Psychology, 68, 151-158.

Mathieu, C., Neumann, C. S., Hare, R. D., \& Babiak, P. (2014). A dark side of leadership: Corporate psychopathy and its influence on employee well-being and job satisfaction. Personality and Individual Differences, 59, 83-88.

Miller, J. D., \& Campbell, W. K. (2008). Comparing clinical and social-personality conceptualizations of narcissism. Journal of personality, 76(3), 449-476.

Miller, J. D., Hoffman, B. J., Gaughan, E. T., Gentile, B., Maples, J., \& Campbell, W. K. (2011). Grandiose and vulnerable narcissism: A nomological network analysis. Journal of Personality, 79, 1013-1042.

Miller, J. D., Hyatt, C. S., Maples-Keller, J. L., Carter, N. T., \& Lynam, D.R. (2016). Psychopathy and Machiavellianism: A distinction without a difference? Journal of Personality, 85, 439-453.

O’boyle, E. H. Jr., Forsyth, D. R., Banks, G. C., \& McDaniel, M. A. (2012). A metaanalysis of the Dark Triad and work behavior: A social exchange perspective. Journal of Applied Psychology, 97, 557-579.

O'Fallon, M. J., \& Butterfield, K. D. (2005). A review of the empirical ethical decisionmaking literature: 1996-2003. Journal of Business Ethics, 59, 375-413.

Öcel, H. (2010). Üretim karşıtı iş davranışları ölçeği: geçerlik ve güvenirlik çalışması. Türk Psikoloji Yazıları, 13, 26, 18-26.

Özsoy, E. (2017). Kişiliğin karanlık yönünün tükenmişlik üzerindeki etkisi. Unpublished doctoral dissertation. Sakarya Üniversitesi, İşletme Bilimi Enstitüsü. Sakarya.

Özsoy, E., Rauthmann, J. F., Jonason, P. K., \& Ardiç, K. (2017). Reliability and validity of Turkish version of Dark Triad Dirty Dozen (DTDD-T), Short Dark Triad (SD3T) and Single Item Narcissism Scale (SINS-T). Personality and Individual Differences, 117, 11-14.

Paulhus, D. L., \& Williams, K. M. (2002). The dark triad of personality: Narcissism, Machiavellianism, and psychopathy. Journal of Research in Personality, 36, 556-563.

Penney, L. M., \& Spector, P. E. (2002). Narcissism and counterproductive work behavior: Do bigger egos mean bigger problems? International Journal of Selection and Assessment, 10, 126-134.

Penney, L. M., \& Spector, P. E. (2002). Narcissism and counterproductive work behavior: Do bigger egos mean bigger problems? International Journal of Selection and Assessment, 10, 126-134.

Raskin, R. N., \& Hall, C. S. (1979). A Narcissistic Personality Inventory. Psychological Reports, 45, 590-590. 
Rauthmann, J. F., \& Will, T. (2011). Proposing a multidimensional Machiavellianism conceptualization. Social Behavior and Personality, 39, 391-404.

Smith, S. F., \& Lilienfeld, S. O. (2013). Psychopathy in the workplace: The knowns and unknowns. Aggression and Violent Behavior, 18, 204-218.

Spain, S. M., Harms, P., \& LeBreton, J. M. (2014). The dark side of personality at work. Journal of Organizational Behaviour, 35, 41-60.

Spector, P. E., \& Fox, S. (2005). A model of counterproductive work behavior. In S. Fox \& P. E. Spector (Eds.), Counterproductive workplace behavior: Investigations of actors and targets (pp. 151-174). Washington, DC: APA.

Spector, P. E., Fox, S., Penney, L. M., Bruursema, K., Goh, A., \& Kessler, S. (2006). The dimensionality of counterproductivity. Journal of Vocational Behavior, 68, 446-460.

Van Geel, M., Toprak, F., Goemans, A., Zwaanswijk, W., \& Vedder, P. (2017). Are youth psychopathic traits related to bullying? Meta-analyses on callousunemotional traits, narcissism, and impulsivity. Child Psychiatry \& Human Development, 48, 768-777.

Volmer, J., Koch, I. K,. \& Göritz, A. S. (2016). The bright and dark sides of leaders' Dark Triad traits: Effects on subordinates' career success and well-being. Personality and Individual Differences, 101, 413-418.

Yin, L., \& Cohen, A. (2018). Dark triad personalities and counterproductive work behaviors among physicians in China. International Journal of Health Planning and Management, 1-14, Doi: 10.1002/hpm.2577. 